\title{
On the strong convergence theorem of Noor iterative scheme in the class of Zamfirescu operators
}

\author{
Mohammad Asaduzzaman ${ }^{1, ~}$, Mohammad Zulfikar Ali ${ }^{2}$ \\ ${ }^{1}$ Department of Mathematics, Islamic University, Kushtia-7003, Bangladesh \\ ${ }^{2}$ Department of Mathematics, University of Rajshahi, Rajshahi-6205, Bangladesh
}

Email address:

masad_iu_math@yahoo.com (M. Asaduzzaman), zulfikar_math_ru@yahoo.com (M. Z. Ali)

To cite this article:

Mohammad Asaduzzaman, Mohammad Zulfikar Ali. On the Strong Convergence Theorem of Noor Iterative Scheme in the Class of Zamfirescu Operators. Pure and Applied Mathematics Journal. Vol. 2, No. 4, 2013, pp. 140-145. doi: 10.11648/j.pamj.20130204.11

\begin{abstract}
In this paper, we establish the strong convergence theorem of Noor iterative scheme for the class of Zamfirescu operators in arbitrary Banach spaces. Our results is extension and generalization of the recent results of B. L. Xu, M. A. Noor, Y. J. Cho, H. Zhou, G. Guo, S. Plubtieng, R. Wangkeeree, V. Berinde, P. Kumam, W. Kumethong, N. Jewwaiworn and many other authors in literature.
\end{abstract}

Keywords: Fixed Point, Mann Iterative Scheme, Ishikawa Iterative Scheme, Noor Iterative Scheme, Zamfirescu Operators, T - Stable

\section{Introduction}

In the last four decades, numerous papers were published on the iterative schemes of fixed points of self and non-self contractive type operators in metric spaces, Hilbert spaces or several classes of Banach spaces, (see for example the reference papers therein). While for strict contractive type operators, the Picard iteration can be used to approximate the (unique) fixed point, (see for example [4, 7-9]), for operators satisfying slightly weaker contractive type conditions, instead of Picard iteration, which does not generally converge, it was necessary to consider other fixed point iteration procedures. The Krasnoselskij iterative scheme [10-13], the Mann iterative scheme [14-16], the Ishikawa iteration scheme [17] and the Noor iterative scheme [18-19], are certainly the most studied of these fixed point iterative schemes, (see for example [6-8, 20]).

Fixed-point iterations process for asymptotically non-expansive mapping in Banach spaces including Mann, Ishikawa and Noor iterative schemes have been studied extensively by many authors to solve the nonlinear operator equations as well as variational inequations, (see for example [9, 11, 14, 17-25]). In 2000, M. A. Noor [18] introduced a three-step iterative scheme and studied the approximate solution of variational inclusion in Hilbert spaces by using the techniques of updating the solution and the auxiliary principle. In 1989, R. Glowinski and Le Tallec [26] used three-step iterative scheme to find the approximate solutions of the elastoviscoplasticity problem, liquid crystal theory, and eigenvalue computation. It has been shown in [26] that the three-step iterative scheme gives better numerical results than the two-step and one-step iterative schemes. In 1998, S. Haubruge, V. H. Nguyen and J. J. Strodiot [27] studied the convergence analysis of three-step iteration scheme of Glowinski and Le Tallec [26] and applied this scheme to obtain new splitting-type algorithms for solving variation inequalities, separable convex programming and minimization of a sum of convex functions. They also proved that three-step iterative scheme lead to highly paralleled algorithms under certain conditions. Thus we conclude that three-step iterative scheme plays an important and significant part in solving various numerical problems, which arise in pure and applied sciences.

Recently, S. Plubtieng and R. Wangkeeree [3] studied on the Strong convergence theorem for multi-step Noor iterations with errors in Banach spaces. In 2002, B. L. Xu and M. A. Noor [1] introduced and studied a three-step iterative scheme to approximate fixed points of asymptotically nonexpansive mappings in Banach spaces. In 2004, Y.J. Cho, H. Zhou, and G. Guo [2] extended the work of $\mathrm{Xu}$ and Noor to the three-step iterative scheme with errors and gave weak and strong convergence theorems for asymptotically nonexpansive mappings in Banach spaces. Moreover, In 2007 J.U. Jeong [22] and in 2008 P. Kumam, W. Kumethong and N. Jewwaiworn [6] gave weak and strong convergence theorems for three-step iterative scheme of asymptotically nonexpansive mappings in Banach spaces. In 2004 and 2007, V. Berinde [28-29] studied the convergence theorems of Mann and Ishikawa iterative 
schemes for Zamfirescu operators in arbitrary Banach spaces. Inspired and motivated by these facts, we extend and generalized the convergence theorem of three-step Noor iterative scheme for more general Zamfirescu operators in arbitrary Banach spaces.

The main purpose of our paper is to establish the strong convergence theorem for three-step Noor iterative scheme for more general operators Zamfirescu operators in arbitrary Banach spaces. The results presented in this paper is extension and generalization of the corresponding results of B. L. Xu and M. A. Noor [1], Y. J. Cho, H. Zhou, and G. Guo [2], S. Plubtieng and R. Wangkeeree [3], V. Berinde [4-5] and many other authors in literature

\section{Preliminaries}

In this section, we recall some well-known concepts and results.

In 1972, T. Zamfirescu [30] obtained a very interesting fixed point theorem which is stated as follows:

\section{Theorem 2.1.}

(Theorem $\mathbf{Z}$ of [30]). Let $X$ be a Banach space and $T: X \rightarrow X$ be a map for which there exist the real number $a, b$ and $c$ satisfying $0<a<1,0<b, c<1 / 2$ such that for each pair $x, y$ in $X$ at least one of the following is true:

$$
\begin{array}{ll}
\left(z_{1}\right) & \|T x-T y\| \leq a\|x-y\| ; \\
\left(z_{2}\right) & \|T x-T y\| \leq b[\|x-T x\|+\|y-T y\|] ; \\
\left(z_{3}\right) & \|T x-T y\| \leq c[\|x-T y\|+\|y-T x\|] .
\end{array}
$$

Then $T$ have a unique fixed point $p$ and the Picard iterative scheme $\left\{x_{n}\right\}_{n=0}^{\infty}$ defined by $x_{n+1}=T x_{n}, n=0,1,2, \ldots$ converge to $p$ for any $x_{0} \in X$.

\section{Definition 2.1.}

Let $X$ be a Banach space. Then the operator $T: X \rightarrow X$ is called Zamfirescu operator if it satisfies one of the conditions $\left(z_{1}\right),\left(z_{2}\right)$ and $\left(z_{3}\right)$. The set of fixed points of the operator $T$ is denoted by $F(T)=\{p \in X: T(p)=p\}$.

The definition 2.1 is used as an important tool to establish our main results.

\section{Definition 2.2.}

Let $X$ be a Banach space, $B$ be a nonempty, convex subset of $X$ and $T: B \rightarrow B$ be an operator satisfying one of the conditions $\left(z_{1}\right),\left(z_{2}\right)$ and $\left(z_{3}\right)$ i.e., $T$ be a Zamfirescu operator. Let $u_{0}, p_{0}$ and $x_{0} \in B$ be three arbitrary points.

The Mann iterative scheme, see [14] $\left\{u_{n}\right\}_{n=0}^{\infty}$ is defined by

$$
u_{n+1}=\left(1-a_{n}\right) u_{n}+a_{n} T u_{n}, \quad n=0,1,2, \ldots
$$

where, the sequence $\left\{a_{n}\right\}_{n=0}^{\infty} \subset[0,1]$ is convergent, such that $\lim _{n \rightarrow \infty} a_{n}=0$ and $\sum_{n=1}^{\infty} a_{n}=\infty$

The Ishikawa iterative scheme, see [17] $\left\{p_{n}\right\}_{n=0}^{\infty}$ is defined by

$$
\left.\begin{array}{c}
p_{n+1}=\left(1-a_{n}\right) p_{n}+a_{n} T q_{n} \\
q_{n}=\left(1-b_{n}\right) p_{n}+b_{n} T p_{n}, \quad n=0,1,2, \ldots
\end{array}\right\}
$$

where, the sequences $\left\{a_{n}\right\}_{n=0}^{\infty}$ and $\left\{b_{n}\right\}_{n=0}^{\infty} \subset[0,1]$ are convergent, such that

$$
\lim _{n \rightarrow \infty} a_{n}=0, \lim _{n \rightarrow \infty} b_{n}=0 \text { and } \sum_{n=1}^{\infty} a_{n}=\infty
$$

The Noor iterative scheme, see [18] $\left\{x_{n}\right\}_{n=0}^{\infty}$ is defined by

$$
\left.\begin{array}{l}
x_{n+1}=\left(1-a_{n}\right) x_{n}+a_{n} T y_{n} \\
y_{n}=\left(1-b_{n}\right) x_{n}+b_{n} T z_{n} \\
z_{n}=\left(1-c_{n}\right) x_{n}+c_{n} T x_{n}, \quad n=0,1,2, \ldots
\end{array}\right\}
$$

where, the sequences $\left\{a_{n}\right\}_{n=0}^{\infty},\left\{b_{n}\right\}_{n=0}^{\infty}$ and $\left\{c_{n}\right\}_{n=0}^{\infty} \subset[0,1]$ are convergent, such that

$$
\lim _{n \rightarrow \infty} a_{n}=0, \lim _{n \rightarrow \infty} b_{n}=0, \lim _{n \rightarrow \infty} c_{n}=0 \text { and } \sum_{n=1}^{\infty} a_{n}=\infty
$$

\section{Remark 2.1.}

It is clear from the definition 2.2, if we put $c_{n}=0$ then the iterative scheme (3) is converted to the iteration scheme (2) and if we put $c_{n}=b_{n}=0$ and $a_{n}=\lambda$ (constant) then the iterative scheme (3) is converted to the iteration scheme (1). Again, if we put $c_{n}=b_{n}=0$ and $a_{n}=\delta$ (constant) then the iteration scheme (3) is converted to the Krasnoselskii iteration scheme [10], while for $a_{n}=1$ we obtain the Picard iteration scheme or method of successive approximations [4], as it is commonly known.

\section{Definition 2.3.}

Let $F(T)=\{p \in X: T(p)=p\}, p \in F(T)$ and 


$$
\begin{aligned}
& \eta_{n}=\left\|u_{n+1}-\left(1-a_{n}\right) u_{n}-a_{n} T u_{n}\right\| \\
& \mu_{n}=\left\|p_{n+1}-\left(1-a_{n}\right) p_{n}-a_{n} T p_{n}\right\| \\
& \xi_{n}=\left\|x_{n+1}-\left(1-a_{n}\right) x_{n}-a_{n} T x_{n}\right\|
\end{aligned}
$$

If $\lim _{n \rightarrow \infty} \eta_{n}=0, \lim _{n \rightarrow \infty} \mu_{n}=0$ and $\lim _{n \rightarrow \infty} \xi_{n}=0$, then the iterative schemes (1), (2) and (3) respectively are said to be T-stable.

\section{Remark 2.2.}

Let $X$ be a Banach space, $B$ be a nonempty, convex subset of $X$ and $T: B \rightarrow B$ be a Zamfirescu operator. If the Noor (respectively Ishikawa and Mann) iterative scheme converges, then $\lim _{n \rightarrow \infty} \xi_{n}=0$ (respectively $\lim _{n \rightarrow \infty} \eta_{n}=0$ and $\left.\lim _{n \rightarrow \infty} \mu_{n}=0\right)$.

\section{Proof of Remark 2.2.}

Let $\lim _{n \rightarrow \infty} x_{n}=x^{*}$. Then from (4.c) we have

$$
\begin{aligned}
0 \leq \xi_{n} & =\left\|x_{n+1}-\left(1-a_{n}\right) x_{n}-a_{n} T x_{n}\right\| \\
& =\left\|x_{n+1}-x_{n}+a_{n}\left(x_{n}-T x_{n}\right)\right\| \\
\leq & \left\|x_{n+1}-x_{n}\right\|+a_{n}\left\|x_{n}-T x_{n}\right\| \\
\leq & \left\|x_{n+1}-x^{*}\right\|+\left\|x_{n}-x^{*}\right\|+a_{n}\left\|x_{n}-x^{*}\right\| \\
& +a_{n}\left\|x^{*}-T x_{n}\right\|
\end{aligned}
$$

$\rightarrow 0$ as $n \rightarrow \infty$. i.e., $\lim _{n \rightarrow \infty} \xi_{n}=0$.

\section{Definition 2.4.}

Let $C$ be a subset of a real normed linear spaces $Y$. Then the mapping $S: C \rightarrow C$ is said to be asymptotically non-expansive on $C$ if $\exists$ a sequence $\left\{r_{n}\right\}_{n=0}^{\infty}$ with $\lim _{n \rightarrow \infty} r_{n}=0 \quad$ such that for each $x, y \in C,\left\|S^{n} x-S^{n} y\right\| \leq\left(1+r_{n}\right)\|x-y\|, \quad \forall n \geq 1$. If $r_{n}=0$, then $S$ is known as a non-expansive mapping. $S$ is called asymptotically non-expansive in the intermediate sense [28] provided $S$ is uniformly continuous and

$$
\lim _{n \rightarrow \infty} \sup _{x \in C} \sup _{y \in C}\left(\left\|S^{n} x-S^{n} y\right\|-\|x-y\|\right) \leq 0 \text {. }
$$

$S$ is said to be asymptotically quasi-non-expansive mapping, if $\exists$ a $\left\{r_{n}\right\}_{n=0}^{\infty}$ with $\lim _{n \rightarrow \infty} r_{n}=0$ such that $\forall x \in C, p \in F(S), \quad\left\|S^{n} x-p\right\| \leq\left(1+r_{n}\right)\|x-p\|$, $\forall n \geq 1$, where $F(S)$ denotes the set of fixed points of $S$, i.e., $F(S)=\{x \in C: S x=x\} . S$ is said to be uniformly $L$-Lipschitzian if $\exists$ a constant $L>0$ such that $\left\|S^{n} x-S^{n} y\right\| \leq L\|x-y\|, \forall n \geq 1$ and $x, y \in C$.

In [28] and [29] V. Berinde proved the following convergence theorems in Banach spaces, for Mann and Ishikawa iterations associated to Zamfirescu operator.

\section{Theorem 2.2.}

(Theorem 2.1 of [28]). Let $X$ be an arbitrary Banach space, $B$ be a nonempty closed convex subset of $X$ and $T: B \rightarrow B$ be an operator satisfying condition $\mathbf{Z}$. Let $\left\{u_{n}\right\}_{n=0}^{\infty}$ be the Mann iteration defined by (1) and (1.a). Then $\left\{u_{n}\right\}_{n=0}^{\infty}$ converges strongly to the fixed point of $T$.

\section{Theorem 2.3.}

(Theorem 2 of [29]). Let $X$ be an arbitrary Banach space, $B$ be a nonempty closed convex subset of $X$ and $T: B \rightarrow B$ be an operator satisfying condition $Z$. Let $\left\{p_{n}\right\}_{n=0}^{\infty}$ be the Ishikawa iteration defined by (2) and (2.a). Then $\left\{p_{n}\right\}_{n=0}^{\infty}$ converges strongly to the fixed point of $T$.

Actually, the main purpose of our paper is to extend the Theorem 2.3 from Ishikawa iterative scheme defined by (2) and (2.a) to Noor iterative scheme defined by (3) and (3.a) for Zamfirescu operators and finally, we have established a $T$ - stablity theorem for Noor iterative scheme defined by (3) and (3.a).

\section{Main Results and Discussion}

In this section, we state and prove our main results.

\section{Theorem 3.1.}

Let $X$ be an arbitrary Banach space, $B$ be a nonempty closed convex subset of $X$ and $T: B \rightarrow B$ be an operator satisfying the condition $\mathbf{Z}$ i.e., $T: B \rightarrow B$ be a Zamfirescu operator. Let $p \in F(T)$ be a fixed point of $T$, where $F(T)$ denotes the set of fixed points of $T$. Let $\left\{x_{n}\right\}_{n=0}^{\infty}$ be the Noor iteration defined by (3) and (3.a) and $x_{0} \in B$, where $\left\{a_{n}\right\},\left\{b_{n}\right\}$ and $\left\{c_{n}\right\}$ are sequences of positive numbers in $[0,1]$ with $\left\{a_{n}\right\}$ satisfying (3.a).

Then The Noor iterative scheme strongly converges to the fixed point $p \in F(T)$.

Proof. By Lemma 2.1, we know that $T$ has a unique fixed point in $B$, say $p$. Consider $x, y \in B$. Since $T$ is a Zamfirescu operator, therefore, at least one of the 
conditions $\left(z_{1}\right),\left(z_{2}\right)$ and $\left(z_{3}\right)$ is satisfied by $T$.

If $\left(z_{2}\right)$ holds, then

$$
\begin{aligned}
& \begin{array}{l}
\|T x-T y\| \\
\quad \leq b[\|x-T x\|+\|y-T y\|] \\
\quad \leq b[\|x-T x\|+[\|y-x\|+\|x-T x\|+\|T x-T y\|]]
\end{array} \\
& \Rightarrow(1-b)\|T x-T y\| \leq b\|x-y\|+2 b\|x-T x\| \\
& \Rightarrow\|T x-T y\| \leq \frac{b}{(1-b)}\|x-y\|+2 \frac{b}{(1-b)}\|x-T x\|
\end{aligned}
$$

If $\left(z_{3}\right)$ holds, then similarly we obtain

$$
\|T x-T y\| \leq \frac{c}{(1-c)}\|x-y\|+2 \frac{c}{(1-c)}\|x-T x\|
$$

Let us denote $\lambda=\max \left\{a, \frac{b}{(1-b)}, \frac{c}{(1-c)}\right\}$

Then we have, $0 \leq \lambda<1$ and in view of $\left(z_{1}\right)$, (5) and (6) we get the following inequality

$$
\|T x-T y\| \leq \lambda\|x-y\|+2 \lambda\|x-T x\|
$$

holds $\forall x, y \in B$.

Now let $\left\{x_{n}\right\}_{n=0}^{\infty}$ be the Noor iteration defined by (3) and (3.a) and $x_{0} \in B$ arbitrary. Then

$$
\begin{aligned}
\left\|x_{n+1}-p\right\| & =\left\|\left(1-a_{n}\right) x_{n}+a_{n} T y_{n}-\left(1-a_{n}+a_{n}\right) p\right\| \\
& =\left\|\left(1-a_{n}\right)\left(x_{n}-p\right)+a_{n}\left(T y_{n}-p\right)\right\| \\
& \leq\left(1-a_{n}\right)\left\|x_{n}-p\right\|+a_{n}\left\|T y_{n}-p\right\|
\end{aligned}
$$

With $x=p$ and $y=y_{n}$ from (8) we obtain

$$
\left\|T y_{n}-p\right\| \leq \lambda\left\|y_{n}-p\right\|,
$$

where, $\lambda$ is given by (7).

Further we have

$$
\begin{aligned}
\left\|y_{n}-p\right\| & =\left\|\left(1-b_{n}\right) x_{n}+b_{n} T z_{n}-\left(1-b_{n}+b_{n}\right) p\right\| \\
& \leq\left(1-b_{n}\right)\left\|x_{n}-p\right\|+b_{n}\left\|T z_{n}-p\right\|
\end{aligned}
$$

Again by (8), this time with $x=p$ and $y=z_{n}$ we find that $\left\|T z_{n}-p\right\| \leq \lambda\left\|z_{n}-p\right\|$

Combining (10), (11) and (12) we obtain,

$\left\|T y_{n}-p\right\| \leq \lambda\left[\left(1-b_{n}\right)\left\|x_{n}-p\right\|+\lambda b_{n}\left\|z_{n}-p\right\|\right]$

Now,

$$
\begin{aligned}
\left\|z_{n}-p\right\| & =\left\|\left(1-c_{n}\right) x_{n}+c_{n} T x_{n}-\left(1-c_{n}+c_{n}\right) p\right\|_{(} \\
& \leq\left(1-c_{n}\right)\left\|x_{n}-p\right\|+c_{n}\left\|T x_{n}-p\right\|
\end{aligned}
$$

From (13) and (14) we get,

$$
\begin{aligned}
& \left\|T y_{n}-p\right\| \\
& \leq \lambda\left[\left(1-b_{n}\right)\left\|x_{n}-p\right\|+\lambda b_{n}\left[\left(1-c_{n}\right)\left\|x_{n}-p\right\|\right.\right. \\
& \left.\left.\quad+c_{n}\left\|T x_{n}-p\right\|\right]\right]
\end{aligned}
$$

Again by (8), this time with $x=p$ and $y=x_{n}$ we

find that $\left\|T x_{n}-p\right\| \leq \lambda\left\|x_{n}-p\right\|$

Now, combining (9), (15) and (16) we obtain,

$$
\begin{aligned}
& \quad\left\|x_{n+1}-p\right\| \\
& \leq\left(1-a_{n}\right)\left\|x_{n}-p\right\|+a_{n}\left[\lambda \left[\left(1-b_{n}\right)\left\|x_{n}-p\right\|\right.\right. \\
& \left.\left.\quad+\lambda b_{n}\left[\left(1-c_{n}\right)\left\|x_{n}-p\right\|+\lambda c_{n}\left\|x_{n}-p\right\|\right]\right]\right] \\
& =\left[1-(1-\lambda)\left(1+\lambda b_{n}+\lambda^{2} b_{n} c_{n}\right) a_{n}\right]\left\|x_{n}-p\right\|
\end{aligned}
$$

Since,

$\left[1-(1-\lambda)\left(1+\lambda b_{n}+\lambda^{2} b_{n} c_{n}\right) a_{n}\right] \leq\left[1-(1-\lambda) a_{n}\right]$. So, from (17) we get,

$\left\|x_{n+1}-p\right\| \leq\left[1-(1-\lambda) a_{n}\right]\left\|x_{n}-p\right\|, n=0,1,2, \ldots$

By (1) we inductively obtain

$\left\|x_{n+1}-p\right\|$

$\leq \prod_{n=0}^{\infty}\left[1-(1-\lambda) a_{k}\right]\left\|x_{0}-p\right\|, n=0,1,2, \ldots$

Using the fact that $0 \leq \lambda<1, a_{n}, b_{n}, c_{n} \in[0,1]$ and $\sum_{n=0}^{\infty} a_{n}=\infty$, we obtain that,

$\lim _{n \rightarrow \infty} \prod_{n=0}^{\infty}\left[1-(1-\lambda) a_{k}\right]=0$

Now, from (19) and (20), we obtain

$\lim _{n \rightarrow \infty}\left\|x_{n+1}-p\right\|=0$

i.e., $\left\{x_{n}\right\}_{n=0}^{\infty}$ converges strongly to the fixed point $p$.

This completes our proof.

Now, we state and prove the stability theorem for Noor iterative scheme. 


\section{Theorem 3.2.}

Let $X$ be an arbitrary Banach space, $B$ be a nonempty closed convex subset of $X$ and $T: B \rightarrow B$ be an operator satisfying the condition $\mathbf{Z}$ i.e., $T: B \rightarrow B$ be a Zamfirescu operator. Let $p \in F(T)$ be a fixed point of $T$, where $F(T)$ denotes the set of fixed points of $T$. Let $\left\{x_{n}\right\}_{n=0}^{\infty}$ be the Noor iterative scheme defined by (3) and (3.a) and $x_{0} \in B$, where $\left\{a_{n}\right\},\left\{b_{n}\right\}$ and $\left\{c_{n}\right\}$ are sequences of positive numbers in $[0,1]$ with $\left\{a_{n}\right\}$ satisfying (3.a). Then the Noor iterative scheme is T-stable.

Proof. From the definition 2.3, we can say that the Noor iterative scheme defined by (3) and (3.a) will be T-stable if $\lim _{n \rightarrow \infty} \xi_{n}=0$, where

$$
\xi_{n}=\left\|x_{n+1}-\left(1-a_{n}\right) x_{n}-a_{n} T x_{n}\right\|
$$

Now, from the remark 2.2, we observe that if the Noor iterative scheme defined by (3) and (3.a) is convergent to a fixed point of $T$ then $\lim _{n \rightarrow \infty} \xi_{n}=0$. But in our theorem 3.1 , we have already proved that the Noor iterative scheme defined by (3) and (3.a) is strongly convergent to a fixed point of $T$.

So, by combining our theorem 3.1 and remark 2.2, we obtain $\lim _{n \rightarrow \infty} \xi_{n}=0$ and this proves that the Noor iterative scheme is T- stable. This completes our theorem.

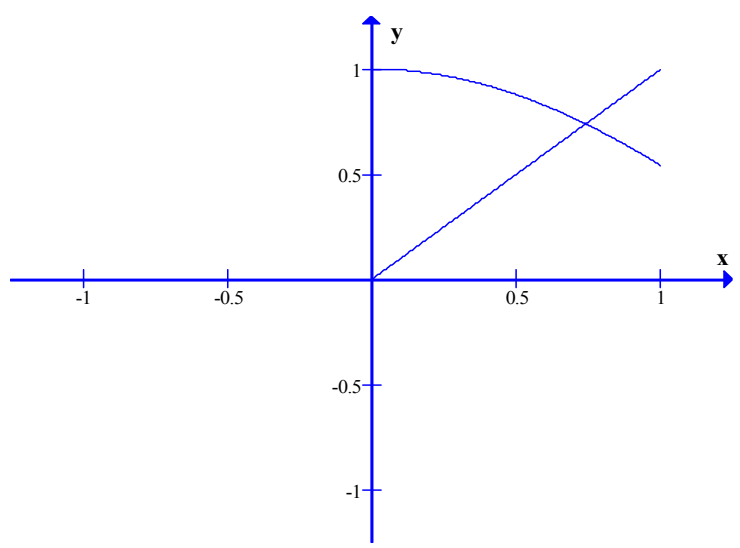

Figure 1: This diagram indicates the graphical representation of the fixed point of the map $T: B \rightarrow B$ defined by $T x=\cos (x)$. Here $x=p=.739 \in B$ is a fixed point of $T$.

\section{Example 3.1.}

Let $X=R$ (set of all real numbers), $B=[0,1]$ and $T: B \rightarrow B$ be a Zamfirescu operator defined by $T x=\cos (x)$. Then it is clear from figure-1 that $x=p=.739 \in B$ is a fixed point of $T$. Now, let us choose the sequences $\left\{a_{n}\right\}_{n=0}^{\infty},\left\{b_{n}\right\}_{n=0}^{\infty} \&\left\{c_{n}\right\}_{n=0}^{\infty}$ such that $a_{n}=\frac{1}{n+1}, b_{n}=\frac{1}{n+2} \& c_{n}=\frac{1}{n+3} \quad$ respectively and $x_{0}=0.2 \in B$ (arbitrary). Then, all conditions of our theorem 3.1 are satisfied. A few step of Noor iterative scheme calculated by MATLAB-7 program are given below:

Table 1: This table shows the different iterative steps and their corresponding approximated value obtained by Noor iterative scheme, where the initial approximation is $x_{0}=0.2 \in B$ (arbitrary). Here we shows that after $224^{\text {th }}$ step the Noor iterative scheme converge to the fixed point $x=p=.739 \in B$.

\begin{tabular}{|c|c|c|c|}
\hline $\begin{array}{l}\text { Iterative } \\
\text { Number } \\
(n)\end{array}$ & $\begin{array}{l}\text { Approximated } \\
\text { value } \\
\text { obtained by } \\
\text { Noor iterative } \\
\text { scheme }\end{array}$ & $\begin{array}{c}\text { Iteration } \\
\text { Number } \\
(n)\end{array}$ & $\begin{array}{l}\text { Approximated } \\
\text { value } \\
\text { obtained by Noor } \\
\text { iterative scheme }\end{array}$ \\
\hline$n=1$ & 0.552163335 & $n=9$ & 0.724558719 \\
\hline$n=2$ & 0.639644297 & $n=10$ & 0.726646147 \\
\hline$n=3$ & 0.675862087 & . & ..................... \\
\hline$n=4$ & 0.694724978 & $n=100$ & 0.738767719 \\
\hline$n=5$ & 0.705939597 & ……… & .......... \\
\hline$n=6$ & 0.713211744 & $n=150$ & 0.738922907 \\
\hline$n=7$ & 0.718226827 & & n......... \\
\hline$n=8$ & 0.721848318 & $n=224$ & 0.739 \\
\hline
\end{tabular}

Under the same condition, if we choice, $x_{0}=0.9 \in B$ then, we obtain the following results:

Table 2: This table shows the different iterative steps and their corresponding approximated value obtained by Noor iterative scheme, where the initial approximation is $x_{0}=0.9 \in B$ (arbitrary). Here we shows that after $282^{\text {th }}$ step the Noor iterative scheme converge to the fixed point $x=p=.739 \in B$.

\begin{tabular}{cccc}
\hline $\begin{array}{c}\text { Iterative } \\
\text { Number } \\
(n)\end{array}$ & $\begin{array}{c}\text { Approximated } \\
\text { value } \\
\text { obtained by } \\
\text { Noor iterative } \\
\text { scheme }\end{array}$ & $\begin{array}{c}\text { Iteration } \\
\text { Number } \\
(n)\end{array}$ & $\begin{array}{c}\text { Approximated } \\
\text { value } \\
\text { obtained by Noor } \\
\text { iterative scheme }\end{array}$ \\
\hline$n=1$ & 0.789330057 & $n=9$ & 0.742836872 \\
$n=2$ & 0.765275279 & $n=10$ & 0.742296103 \\
$n=3$ & 0.755600177 & $\ldots \ldots \ldots \ldots$ & $\ldots \ldots \ldots \ldots$ \\
$n=4$ & 0.750622983 & $n=100$ & 0.739165483 \\
$n=5$ & 0.747683732 & $\ldots \ldots \ldots \ldots$ & $\ldots \ldots \ldots \ldots$ \\
$n=6$ & 0.745785723 & $n=150$ & 0.739126877 \\
$n=7$ & 0.744480482 & $\ldots \ldots \ldots \ldots$ & $\ldots \ldots \ldots \ldots$ \\
$n=8$ & 0.743539830 & $n=282$ & 0.739 \\
\hline
\end{tabular}

\section{Conclusion}

Our Theorem 3.1 is an extension of the result of $\mathrm{V}$. Berinde [28-29], because here we have replaced Mann and Ishikawa iterative schemes by Noor iterative scheme and Noor iterative scheme is more general iterative scheme comparing with Mann, Ishikawa, Picard and Krasnoselskij 
iterative schemes. Our results is extension and generalization of the results of B.L. Xu, and M.A. Noor [1], Y.J. Cho, H. Zhou, and G. Guo [2], S. Plubtieng and R. Wangkeeree [3], P. Kumam, W. Kumethong and N. Jewwaiworn [6], because here we have used the more general operator Zamfirescu operator in place of asymptotically nonexpansive operator, asymptotically quasi-nonexpansive operator and uniformly $L$ - Lipschitzian operator.

\section{References}

[1] B. L. Xu and M. A. Noor, Fixed-point iteration for asymptotically nonexpansive mapping in Banach spaces, J. Math. Anal. Appl., 267, 444-453 (2002).

[2] Y. J. Cho, H. Zhou, and G. Guo, Week and strong convergence theorems for three-step iterations with errors for asymptotically nonexpansive mappings, Comput. Math. Appl. 47, 707-717 (2004)

[3] S. Plubtieng and R. Wangkeeree, Strong convergence theorem for multi-step Noor iterations with errors in Banach spaces, (available online 16 September 2005).

[4] V. Berinde, Iterative Approximation of Fixed Points, Editura Efemeride, Baia Mare, (2002).

[5] V. Berinde, The Picard iteration converges faster than Mann iteration for a class of Fixed point Theory and Applications, 1, 1-9, (2004).

[6] P. Kumam, W. Kumethong and N. Jewwaiworn, Weak Convergence Theorems of Three-Step Noor Iterative Scheme for I-quasi-nonexpansive Mappings in Banach Spaces, Applied Mathematical Sciences, 2 59, 2915 - 2920 (2008).

[7] I. A. Rus, Principles and Applications of the Fixed Point Theory, (Romanian) Editura Dacia, Cluj-Napoca (1979).

[8] I. A. Rus, Generalized Contractions and Applications, Cluj University Press, Cluj-Napoca (2001).

[9] W. A. Kirk, and B. Sims, Handbook of Metric Fixed Point Theory, Kluwer Academic Publishers (2001).

[10] M. A. Krasnoselskij, Two remarks on the method of successive approximations, (Russian), Uspehi Mat. Nauk. 10, no. 1 (63), 123-127 (1955).

[11] F. E Browder, and W. V. Petryshyn, Construction of fixed points of nonlinear mappings in Hilbert spaces, J. Math. Anal. Appl. 20, 197-228 (1967).

[12] R. Kannan, Some results on fixed points, III Fund. Math. 70, 169-177 (1971).

[13] R. Kannan, Construction of fixed points of a class of nonlinear mappings, J. Math. Anal. Appl. 41, 430-438 (1973).

[14] W. R. Mann, Mean value methods in iteration, Proc. Amer. Math. Soc. 4, 506-510 (1953).

[15] C. W. Groetsch, A note on segmenting Mann iterates, J. Math.
Anal. Appl. 40, 369-372 (1972).

[16] B. E. Rhoades, Fixed point iterations using infinite matrices, Trans. Amer. Math. Soc., 196, 161-176 (1974).

[17] S. Ishikawa, Fixed points by a new iteration method, Proc. Amer. Math. Soc. 44, 147-150 (1974).

[18] M. A. Noor, New approximation schemes for general variational inequalities, J. Math. Anal. Appl., 251, 217-229 (2000).

[19] M. A. Noor, Three-step iterative algorithms for multivalued variational inclusions, J. Math. Anal. Appl., 255, 589-604 (2001).

[20] B. E. Rhoades, Fixed point iterations for certain nonlinear mappings, J. Math. Anal. Appl. 183, 118-120 (1994).

[21] J.U. Jeong, M. A. Noor and A. Rafiq, Noor iterations for nonlinear Lipschitizian strongly accretive mapping, J. Korea Soc. Math. Educ. Ser. B Pure Appl. Math. 11339-350 (2004).

[22] J.U. Jeong, Jeong, Weak and strong convergence of the Noor iteration process for two asymptotically nonexpansive mappings, J. Appl. Math. \& Computing 23 1-2, 525-536 (2007).

[23] M. A. Noor, T. M. Rassias and Z. Huang, Three-step iteration for nonlinear accretive operator equations, J. Math. Anal. Appl., 274, 59-68 (2002).

[24] Q. Liu, Iterations sequence for asymptotically quasi-nonexpansive mapping with an error member, J. Math. Anal. Appl. 259, 18-24 (2001).

[25] T. H. Kim, J.W. Choi, Asymptotic behavior of almost-orbits of non-Lipschitizian mapping in Banach spaces, Math. Japon. 38 191-197 (1993).

[26] R. Glowinski and Le Tallec, Augmented Lagrangian and Operator-Splitting Methods in Nonlinear Mechanics, SIAM, Philadelphia, (1989).

[27] S. Haubruge, V.H. Nguyen, and J.J. Strodiot, Convergence analysis and applications of Glowinski-Le Tallec splitting method for finding a zero of the sum of two maximal monotone operators, J. Optim Theory Appl. 97 645-673 (1998).

[28] V. Berinde, A convergence of the Mann iteration in the class Zamfirescu operators, Analele Universit at, ii de Vest, Timi soara, Seria Matematic ${ }^{` a}-$ Informatic $^{`}$ a, XLV, 1, 33-41 (2007).

[29] V. Berinde, On the convergence of the Ishikawa iteration in the class of quasi contractive operators, Acta Math. Univ. comenianae, LXXIII, 1, 19-126 (2004).

[30] T. Zamfirescu, Fix point theorems in metric spaces, Arch. Math. (Basel), 23, 292-298 (1972).

[31] S. Banach, Sur les operations dans les ensembles assembles abstraits et leur Applications aux equations integrals,Fund. Math. 3, 133-181 (1922).

[32] D. R. Smart, Fixed point theorems (Book), Cambridge University Press, (1974). 